\title{
Caries incidence following restoration of shortened lower dental arches in a randomized controlled trial
}

\author{
N. J. A. Jepson, ' P. J. Moynihan, ${ }^{2}$ P. J. Kelly, ${ }^{3}$ G. W. Watson, ${ }^{4}$ and J. M. Thomason, ${ }^{5}$
}

\begin{abstract}
Context Removable partial dentures used to restore the shortened lower dental arch may adversely affect the remaining natural teeth and are associated with a low prevalence of use.

Objective To report the findings for caries incidence 2 years after restoration of lower shortened arches with bilateral cantilever resin-bonded bridges (RBBs) and conventional partial dentures (RPDs).

Design Randomised controlled trial.

Setting Secondary care

Patients 25 male and 35 female subjects of median age 67 years. were randomly allocated to 'bridge' and 'denture' treatment groups of 30 patients each matched for age and sex. Caries incidence was recorded during dental examinations 3 months, 1 and 2 years after insertion of new lower prostheses.

Interventions Cantilever RBBs and conventional RPDs with cast metal frameworks.

Results There was a highly significant difference in the frequency of new caries lesions, 11 and 51 in the bridge and denture groups respectively $(P<0.01) .20$ out of 27 bridge patients and 9 of 23 denture patients had no caries experience. Multivariate modeling identified treatment group as the only significant predictor of caries occurrence.

Conclusions Two years after restoration of lower shortened arches for an elderly sample of patients, there was a significantly greater incidence of new and recurrent caries lesions in subjects restored with RPDs compared with cantilever RBBs.
\end{abstract}

$\mathrm{R}$ estoration of the severely shortened lower dental arch has traditionally been effected with a bilateral free-end saddle partial denture. These dentures are provided to restore appearance and masticatory function and, when present, the stability of an opposing complete upper denture.

Removable partial dentures (RPDs) may adversely affect the remaining natural teeth. A number of longitudinal studies have reported an increased incidence of caries and periodontal breakdown when RPDs are worn. ${ }^{1-5}$ This is particularly so for the elderly where there is growing evidence for an association between wearing partial dentures and root surface caries. ${ }^{6-9}$

${ }^{1}$ Senior Lecturer, ${ }^{4}$ Clinical Research Hygienist, ${ }^{5}$ Senior Lecturer, Department of Restorative Dentistry, The Dental School, University of Newcastle upon Tyne, Newcastle upon Tyne; ${ }^{2}$ Lecturer, Departments of Child Dental Health and Oral Biology, The Dental School, University of Newcastle upon Tyne, Newcastle upon Tyne; ${ }^{3}$ Centre for Health \& Medical Research, University of Teeside, Middlesborough

Correspondence to: Dr N. J. A. Jepson, Department of Restorative Dentistry, The Dental School, Framlington Place, Newcastle upon Tyne NE2 4BW

email:n.j.a.jepson@ncl.ac.uk

REFEREED PAPER

Received 13.07.00; Accepted 08.01.01

(c) British Dental Journal 2001; 191: 140-144
The biological price associated with the use of these dentures is, in a sense, offset by reports indicating a low prevalence of use for lower bilateral free-end saddle dentures. Findings of some $30-50 \%$ of patients never or only occasionally wearing their denture have been commonly reported. ${ }^{10-13}$ Clearly, this represents a considerable waste of time and resources. Given the trend for increasing numbers of older adults with natural teeth, ${ }^{14}$ research into cost effective and efficient alternatives to partial dentures would seem timely.

The use of fixed prostheses rather than conventional removable prostheses to restore part of the lower dentition for such patients offers the advantage of less bulk, a more normal contour and, it is anticipated, a more profound effect upon patient acceptance. Cantilever resin-bonded bridges are simple, non-destructive and cost effective fixed restorations. ${ }^{15,16}$ When applied to the severely shortened lower dental arch, they appeared to offer a clinically effective restoration that was well accepted by patients.

A randomised clinical trial has been established to compare the effectiveness of bilateral cantilever resin-bonded bridges and conventional partial dentures when restoring shortened lower dental arches. The a priori hypothesis was that restoration with cantilever resin-bonded bridges was as effective as the use of RPDs. Primary outcome measures were survival and the influence on dietary selection and nutrient intake. Additional outcomes included patient satisfaction, caries and periodontal status. This paper reports the findings for caries incidence after 2 years use of new lower prostheses in this ongoing clinical trial.

\section{Materials and methods}

\section{Protocol}

Male or female adult subjects were drawn from dental hospital patients awaiting the provision of a lower bilateral free-end saddle denture. Following a clinical and radiographic examination, suitability was established using the criteria listed in Table 1 . They were then given written and visual information. These patients received the following preparatory treatment: a course of oral hygiene instruction, including the use of interdental cleaners, and scaling; periodontal therapy as necessary and the restoration of caries and replacement of defective restorations. Patients were required to achieve plaque and gingival indices of $20 \%$ or less and demonstrate the effective use of floss or interdental brushes in order to enter the trial. Written consent was obtained from all subjects.

All new prostheses were constructed to agreed clinical protocols and were fitted over the period June 1995 to July 1997. Cantilever resin bonded bridges restored one occlusal unit, up to but not beyond the second premolar, using single pontics cantilevered from single abutments whenever possible. Abutment teeth were prepared to ensure wrap round and positive seating and full lingual coverage was used for premolar abutments (Fig. 1). Lower free-end saddle partial dentures were constructed using cast metal 


\section{RESEARCH $\underline{\text { restorative dentistry }}$}

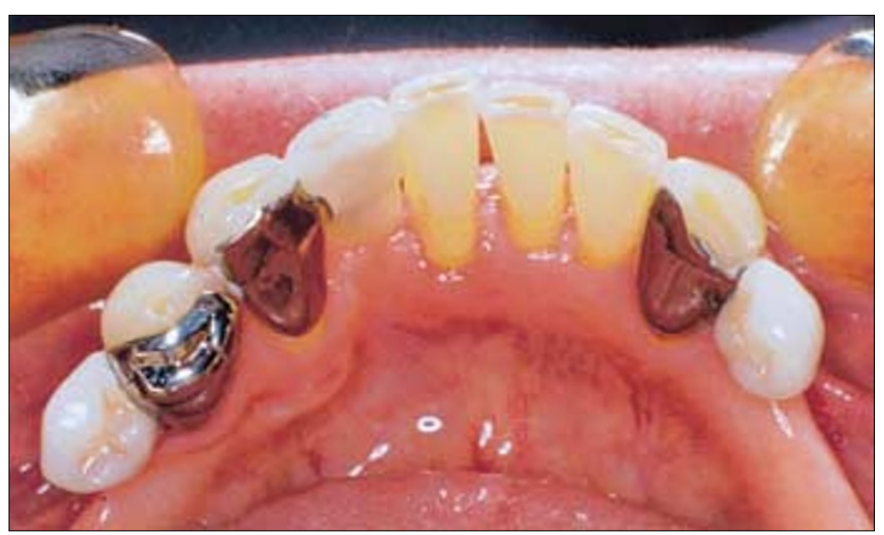

Fig. I Cantilever resin bonded bridges showing the use of maximum bonding area, wrap-round and full lingual coverage of the lower premolar

Table I Inclusion and exclusion criteria

\begin{tabular}{ll} 
Inclusion & Exclusion \\
\hline $\begin{array}{l}\text { Maximum } 8 \text { remaining lower teeth } \\
\begin{array}{l}\text { I to 2 tooth anterior spaces allowed } \\
\text { provided they were restorable }\end{array}\end{array}$ & $\begin{array}{l}\text { Lower molars } \\
\text { by a proposed lower prosthesis }\end{array}$ \\
$\begin{array}{l}\text { Plaque and gingival indices of } \\
20 \% \text { or less }\end{array}$ & $\begin{array}{l}\text { Relevant medical history or } \\
\text { prescribed diet }\end{array}$ \\
\hline
\end{tabular}

frameworks that incorporated rests, retainers and a rigid connector. The design of the connector was clinically determined and reflected factors such as the presence of anterior modification spaces, depth of the anterior lingual sulcus and the position of lingual frenal attachments. Altered cast procedures were used as required. Where present, upper dentures were replaced along with the provision of new lower prostheses.

A target sample size of 60 patients, 30 in each intervention group, was projected as having a $80 \%$ chance of detecting clinically significant variations in prosthesis failure rate and nutritional intake between groups.

The incidence of new or recurrent caries, defective restorations, endodontic complications and tooth fracture was recorded during dental examinations at 3 months, 1 and 2 years after insertion of the new lower prosthesis. Caries was recorded as present when there was frank cavitation that required restoration. Root caries lesions were not recorded as a carious incidence if there was initial decalcification but a seemingly intact surface that might be stabilized by fluoride application. Two operators (NJAJ, JMT), calibrated for the diagnosis and recording of caries, were involved in the diagnosis of caries. Further review and maintenance appointments were scheduled as was clinically required. In addition, one dental hygienist at three-monthly reviews recorded the periodontal status. Plaque control was reinforced at each of these reviews as was necessary.

Examination of the data was undertaken using univariate and multivariate regression analyses. Statistical significance was accepted at the $5 \%$ level.

\section{Assignment}

Patients who failed to satisfactorily complete preparatory treatment, or were assessed as unsuitable for inclusion at the preliminary clinical evaluation, were directly allocated to normal clinics for their continued treatment. Patients who satisfactorily completed any necessary preparatory treatment were randomly allocated by gender, stratified by age to 'bridge' or 'denture' treatment groups according to computer generated random numbers. The clinician was not involved in this allocation. However, no attempt was made to separate persons providing intervention from those assessing outcome. Two operators (NJAJ, JMT) saw an equal number of bridge and denture patients and carried out all subsequent dental examinations.

\section{Results}

Participant flow and follow-up

The profile of this randomised clinical trial is given in Figure 2 that summarizes patient numbers, flow, randomization and timing of interventions. Sixty-five patients were assessed as potentially suitable to take part in the study. All agreed though subsequently 1 patient withdrew and 4 patients failed to achieve adequate levels of plaque control and were not entered into the study. Sixty subjects entered the study, 25 male and 35 female, of median age 67 years (minimum 39 and maximum 81 years) and were allocated to 'bridge' and 'denture' treatment groups of 30 patients each. The median number of remaining lower teeth was 7 (minimum 3 and maximum 8 ). There were 61 sound unrestored abutment teeth and 46 sound restored abutment teeth. Twenty-six of the 30 lower RPDs used plate connectors. For 51 patients lower prostheses opposed a complete upper denture, 7 a partial upper denture and 2 upper natural teeth only. There were no significant differences in these baseline descriptions between groups.

At 2 years there had been 3 withdrawals from the bridge group and 7 from the denture group. All withdrawals were for personal reasons or because of ill health or death. Six patients never or only occasionally used their lower RPD.

\section{Analysis}

The first new or recurrent caries lesion on each tooth was recorded. Table 2 details the frequency of these first occurrences

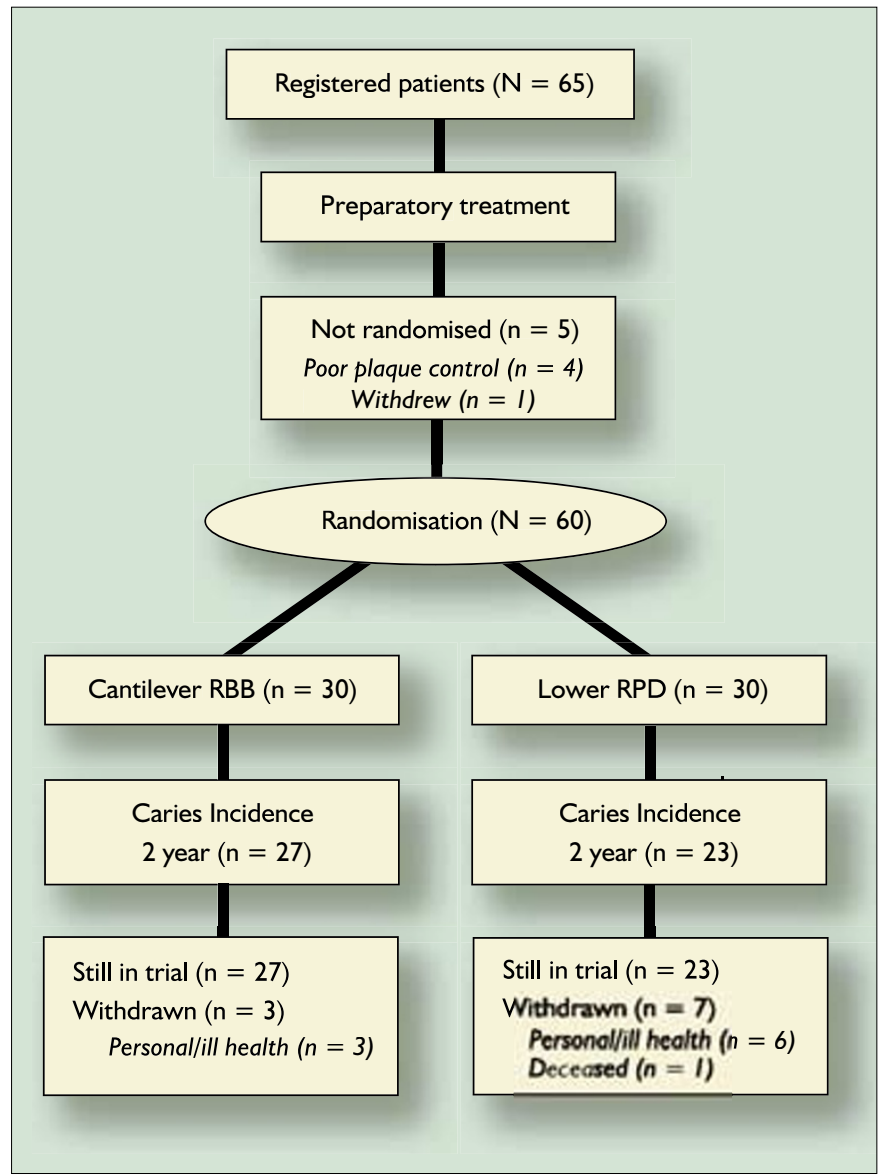

Fig. 2 Profile of randomised clinical trial 
Fig. 3 New and recurrent caries incidence for abutment and nonabutment teeth over 2 years

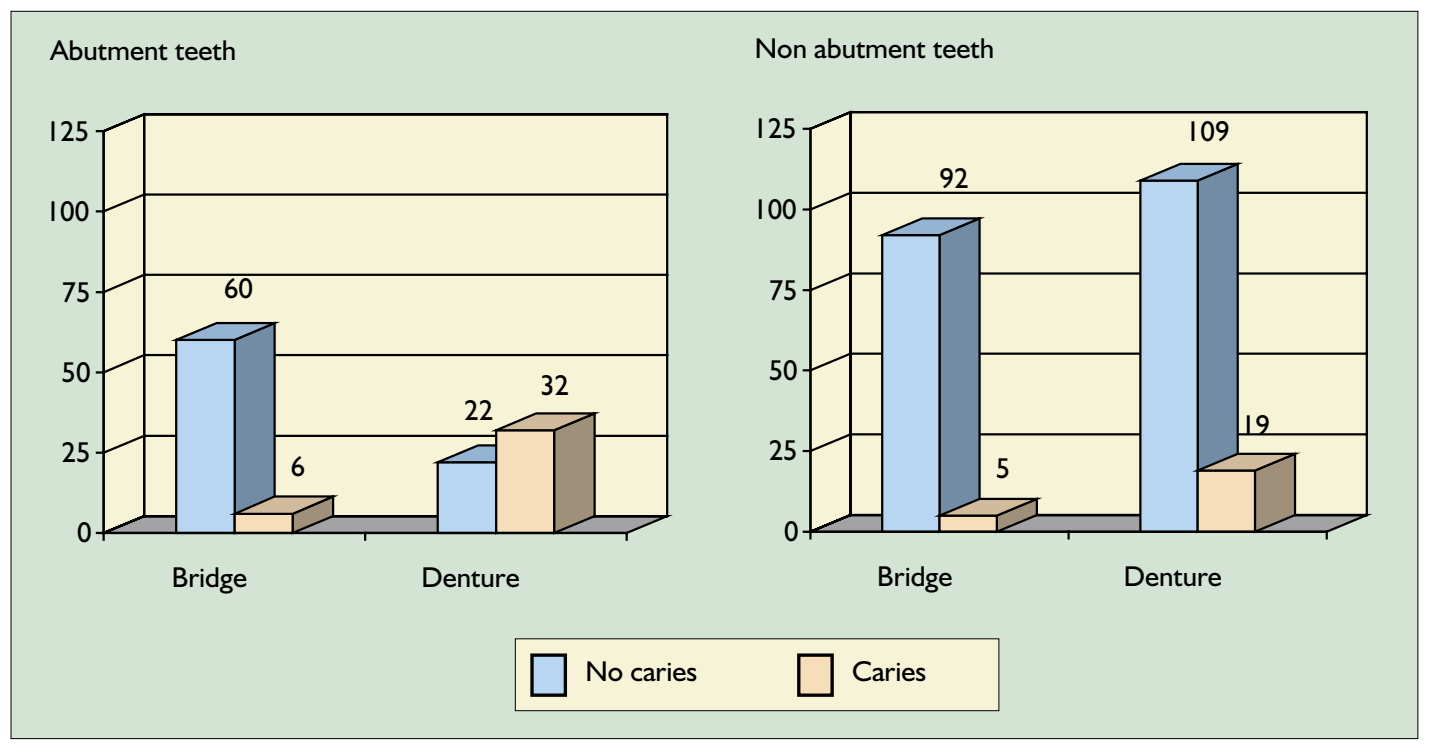

Table 2 Incidence of new and recurrent carious lesions and tooth fracture by treatment group after 2 years use of lower prostheses

\begin{tabular}{lccccc}
\hline & $\begin{array}{c}\text { No } \\
\text { caries }\end{array}$ & $\begin{array}{c}\text { New } \\
\text { caries }\end{array}$ & $\begin{array}{c}\text { Recurrent } \\
\text { caries }\end{array}$ & $\begin{array}{c}\text { Tooth } \\
\text { fracture }\end{array}$ & All \\
\hline Bridge & 153 & 11 & 0 & 1 & 165 \\
Denture & 102 & 37 & 14 & 3 & 156 \\
\hdashline All & 255 & 48 & 14 & 4 & 321 \\
\hline
\end{tabular}

and tooth fracture two years after provision of new lower prostheses. Of the 165 remaining natural teeth in the bridge group there were 11 new carious lesions and one tooth fracture. This compared with 51 new or recurrent carious lesions and 3 fractures of 156 available teeth in the denture group. Differences between the groups were highly significant $(P<0.01)$. Figure 3 illustrates the distribution of this incidence of new and recurrent caries between abutment and non-abutment teeth and reveals even clearer differences between treatment groups. In the bridge group there is little difference between non-abutment and abutment teeth, a caries incidence of $14 \%$ and $9 \%$ respectively. This compares with a caries incidence of $14 \%$ for non-abutments and $60 \%$ for abutments in the denture group. 20 out of 27 bridge patients had no caries experience over 2 years and only 1 patient more than 3 carious lesions. In the denture group, 7 patients experienced 3 or more caries incidents. Clinically, caries within this subgroup of patients frequently manifested itself as root caries. A typical example of this pattern of caries incidence is shown in Figure 4.

Using caries occurrence as the dichotomous outcome variable, the risk posed by a range of demographic and clinical variables identifiable at baseline was examined univariately using logistic regression analysis. Descriptive statistics by treatment group for these baseline variables used in the regression analysis are given in Table 3. The results of the analysis are presented in Table 4 in the form of odds ratios and $95 \%$ confidence intervals. A significant risk was only identified for the variable treatment group. Logistic estimates for caries occurrence using treatment group as the predictor are given in Table 5. The other variables listed in Table 4 were then introduced into this model in turn but they failed to materially alter the outcome.

\section{Discussion}

There have been very few randomised clinical trials that have examined the effectiveness of either resin-bonded bridgework or removable partial dentures. ${ }^{13,17}$ The advantages of such a study design are well recognised. They are prospective and allow a clear comparison of treatment effects through the control, randomisation of other variables within the study population. In particular, the possibility of clinical bias, an inevitable feature of, for example, observed cohort studies, is eliminated. The number of patients used in this trial afforded the study the power to identify clinically relevant differences in the effects of the two treatments and would be widely accepted as reasonable and practical for a randomised efficacy trial of this nature. Given the age of the study patients, the number of withdrawals reported is unsurprising although the higher number of withdrawals in the denture group may have reflected disappointment with their treatment allocation. Bias in the reporting of caries incidence was possible given a study design in which the operators providing treatment also assessed its treatment. However, blinding of an independent examiner to the treatment interventions is clearly not possible and a source of bias could remain.

The finding of a relative risk of new caries that was nearly four times greater in the denture group as compared with the bridge group bears a striking resemblance to the findings of Budtz-Jorgensen et al. ${ }^{5}$ for a similar study population. The increase in caries incidence within the denture group and, in particular, of abutment teeth, corroborates the findings of earlier longitudinal ${ }^{1-4}$ and more recent epidemiological studies ${ }^{7-9,18}$ of the effects of removable partial dentures. The data for the denture group included the significant minority of patients who no longer wore their dentures. Their influence on caries incidence was difficult to interpret simply

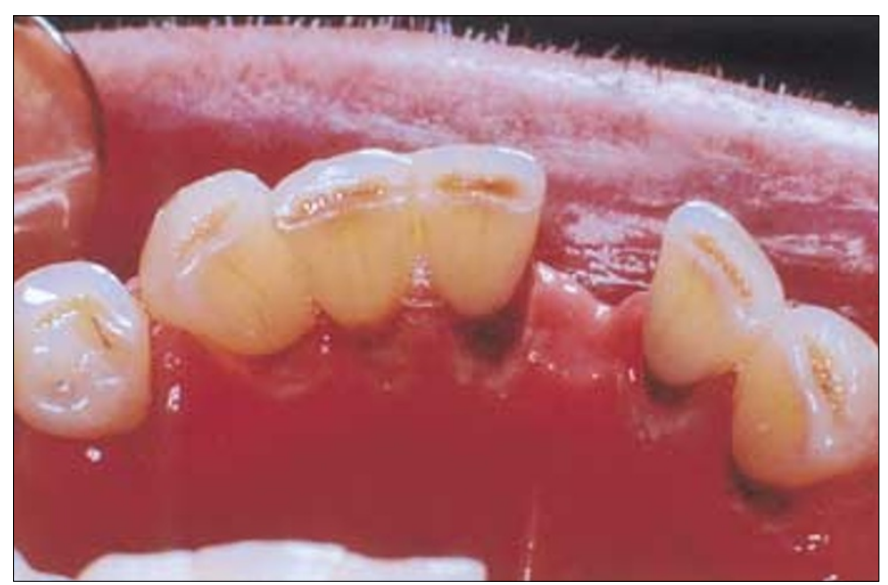

Fig. 4 A typical example of root caries occurrence in a patient wearing a lower RPD 
Table 3 Descriptive statistics by treatment group for the baseline variable data used in the regression analyses

\begin{tabular}{|c|c|c|c|c|c|c|}
\hline \multirow[b]{2}{*}{ Baseline variable } & \multicolumn{3}{|c|}{ Bridge } & \multicolumn{3}{|c|}{ Denture } \\
\hline & $\mathrm{N}$ & Mean & $\begin{array}{l}\text { Standard } \\
\text { deviation }\end{array}$ & $N$ & Mean & $\begin{array}{l}\text { Standard } \\
\text { deviation }\end{array}$ \\
\hline Treatment group & 30 & & & 29 & & \\
\hline $\begin{array}{l}\text { Sex male } \\
\text { female }\end{array}$ & $\begin{array}{l}12 \\
16\end{array}$ & & $\begin{array}{l}12 \\
17\end{array}$ & & & \\
\hline Age & 30 & 64.67 & 8.46 & 29 & 65.00 & 10.15 \\
\hline No. remaining lower teeth & 30 & 6.53 & 1.13 & 29 & 6.69 & 1.23 \\
\hline Plaque index & 28 & $0.23^{*}$ & & 27 & $0.28 *$ & \\
\hline Attachment level & 25 & 10.25 & 1.93 & 26 & 10.12 & 1.98 \\
\hline Sugar intake ${ }^{\dagger}$ & 30 & 3.30 & 2.45 & 27 & 4.11 & 3.32 \\
\hline Xerostomia $^{\ddagger}$ none & 23 & & & 24 & & \\
\hline possible & 6 & & & 5 & & \\
\hline
\end{tabular}

*Median value

†Daily frequency of sugar intake.

‡Variable derived from the use or non-use of drugs that may induce dry mouth. No patient had a diagnosed xerostomia

Table 4 Logistic regression using the dichotomous variable caries occurrence as the outcome variable

\begin{tabular}{lccccc}
\hline Baseline variable & $\mathrm{N}$ & Odds ratio & $P$-value & $95 \% \mathrm{Cl}$ \\
\hline & & & & & \\
Treatment group & 49 & 5.19 & 0.009 & 1.50, & 17.89 \\
Sex (male=I, female =2) & 49 & 0.50 & 0.240 & 0.16, & 1.59 \\
Age (years) & 49 & 1.02 & 0.636 & 0.95, & 1.09 \\
No. remaining lower teeth & 49 & 0.85 & 0.508 & 0.52, & 1.39 \\
Plaque index & 47 & 1.51 & 0.675 & 0.22, & 10.31 \\
Attachment level (mm) & 47 & 0.89 & 0.444 & 0.66, & 1.20 \\
Sugar intake & 47 & 1.08 & 0.489 & 0.87 & 1.35 \\
Xerostomia & 48 & 2.00 & 0.354 & 0.46, & 8.65 \\
\hline
\end{tabular}

because the time at which they chose to stop wearing their dentures varied considerably. However, in that these patients were analogous to the 'control' patients of the longitudinal study of Carlsson et al., ${ }^{1}$ the effect is likely to have been an understatement of caries incidence for denture wearers. There was striking evidence of a varying incidence of caries within those patients provided with partial dentures. Over half of the caries within this group occurred in a little under a third of the patients, with root caries a prominent feature. The presence of a lower partial denture is clearly implicated in this process, such effects were not seen in the bridge group. The large majority of these dentures had plate connectors and it would be tempting to simply explain an increased incidence in caries to increased plaque levels associated with gingival coverage. BudtzJorgensen et al., ${ }^{5}$ however, reported similar levels of caries for partial denture wearers in which the dentures were designed to avoid gingival coverage.

The prediction of the development of caries with a high degree of probability is complicated ${ }^{19}$ and the univariate modeling resulting from this study should be treated with some caution. Though reasonably robust, it is possible that other risk factors have not been identified in this study. It is interesting to speculate as to why plaque index was not identified as a risk factor for caries. Partial denture use is firmly associated with increased plaque accumulation and plaque is the principal aetiologic agent for caries. This may simply reflect the relatively small number of patients in the study and a lack of power to detect an effect of changes in plaque index.

This study raises the interesting clinical principle that for elderly patients preservation of remaining teeth is best served by the use of simple fixed prostheses. Such an approach could be considered contrary to more traditional clinical indications for the appropriate use of fixed prostheses. It is, however, consistent with many of the principles of the shortened dental arch concept ${ }^{20}$ and is supported by the current evidence-base associating partial denture use, caries, plaque control and age. ${ }^{7-9,21,22}$
Table 5 Logistic estimate for caries occurrence using treatment group as the predictor

\begin{tabular}{lccc}
\hline Variable & Odds ratio & $P$ value & $95 \% \mathrm{Cl}$ \\
\hline Treatment group & 5.19 & 0.009 & $1.50,17.89$ \\
\hline
\end{tabular}

Observed

\begin{tabular}{lccc}
\hline Classified & Positive & Negative & Total \\
\hline Positive & 14 & 9 & 23 \\
Negative & 6 & 20 & 26 \\
\hline Total & 29 & 29 & 49 \\
\hline
\end{tabular}

$\begin{array}{llll}\text { Model sensitivity } & 70 \% & \text { Model specificity } & 69 \% \\ \text { False positive rate } & 39 \% & \text { False negative rate } & 23 \% \\ \text { Positive predictive value } & 61 \% & \text { Negative predictive value } & 77 \%\end{array}$

A recent survey of elderly adults in the UK by Steele et al. ${ }^{23}$ found that approximately a quarter of all dentate subjects were edentulous in one arch, most often the upper. It is a common pattern of tooth loss in which, for patients in this study, cantilevered resin bonded bridges offered an alternative to conventional lower partial dentures at a lower biological price.

\section{Conclusions}

In a randomised clinical trial to compare the effectiveness of cantilever resin bonded bridges and lower removable partial dentures in restoring shortened lower dental arches of elderly patients, there was a significantly greater incidence of new and recurrent carious lesions in patients provided with RPDs for which a third had three or more caries lesions. Multivariate modeling identified treatment group as a significant risk factor for caries occurrence. 


\section{RESEARCH \\ restorative dentistry}

This investigation was funded by the NHS Executive, Northern \& Yorkshire, Research and Development Directorate, Durham, UK. The authors would like to acknowledge the assistance of support staff within the Department of Prosthodontics, Newcastle Dental Hospital and, in particular, the invaluable contribution of Josie Davison and Jan Thompson to the conduct of this trial.

1 Carlsson G E, Hedegard B, Koivumaa K K. Studies in partial dental prosthesis. IV. Final results of a 4-year longitudinal investigation of dentogingivally supported partial dentures. Acta Odontologica Scand 1965; 23: 443-472.

2 Chandler J A, Brudvik J S. Clinical evaluation of patients eight to nine years after placement of removable partial dentures. J Prosthet Dent 1984; 51: 736-743.

3 Lappalainen R, Koskenranta-Wuorinen P, Markkanen H. Periodontal and cariological status in relation to different combinations of removable dentures in elderly men. Gerodontics $1987 ; 3: 122-124$.

4 Tuominen R, Ranta K, Paunio I. Wearing of removable partial dentures in relation to dental caries. J Oral Rehabil 1988; 15: 515-520.

5 Budtz-Jorgensen E, Isidor F. A 5-year longitudinal study of cantilevered fixed partial dentures compared with removable partial dentures in a geriatric population. J Prosthet Dent 1990; 64: 42-47.

6 Wright P S, Hellyer P H, Beighton D, Heath R, Lynch E. Relationship of removable partial denture use to root caries in an older population. Int $J$ Prosthodont 1992; 5: 39-46.

7 Drake C W, Beck J D. The oral status of elderly removable partial denture wearers. J Oral Rehabil 1993; 20: 53-60.

8 Locker D. Incidence of root caries in an older Canadian population. Community Dent \& Oral Epidemiol 1996; 24: 403-407.

9 Steele J G, Walls A W, Murray J J. Partial dentures as an independent indicator of root caries risk in a group of older adults. Gerodontology 1997; 14: $67-74$

10 Tomlin H R, Osborne J. Cobalt-chromium partial dentures. A clinical survey. Br Dent J 1961; 111: 307-310.
11 Wetherell J D, Smales R J. Partial denture failures: a long-term clinical survey. J Dent 1980; 8: 333-340.

12 Jepson N J A, Thomason J M, Steele J G. The influence of denture design on patient acceptance of partial dentures. Br Dent J 1995; 178: 296-300.

13 Kapur K K, Deupree R, Dent R J, Hasse A L. A randomized clinical trial of two basic removable partial denture designs. Part I: Comparisons of fiveyear success rates and periodontal health. J Prosthet Dent 1994; 72: 268-282.

14 Kelly M et al. Adult Dental Health Survey: Oral health in the United Kingdom 1998. London: HMSO, 2000.

15 Creugers N H, Kayser A F. A method to compare cost-effectiveness of dental treatments: adhesive bridges compared to conventional bridges. Community Dent Oral Epidemiol 1992; 20: 280-283.

16 Hussey D L, Linden G J. The clinical performance of cantilevered resinbonded bridgework. J Dent 1996; 24: 251-256.

17 Creugers N H, De Kanter R J, Verzijden C W, Van't Hof M A. Risk factor and multiple failures in posterior resin-bonded bridges in a 5-year multipractice clinical trial. J Dent 1998; 26: 397-402.

18 Mojon P, Rentsch A, Budtz-Jorgensen E. Relationship between prosthodontic status, caries, and periodontal disease in a geriatric population. Int J Prosthodont 1995; 8: 564-571.

19 Ericson G, Nilson H, Bergman B. Cross-sectional study of patients fitted with fixed partial dentures with special reference to the caries situation. Scand J Dent Res 1990; 98: 8-16.

20 Allen P F, Witter D J, Wilson N H. The role of the shortened dental arch concept in the management of reduced dentitions. Br Dent J 1995; 179: 355-357.

21 MacEntee M I, Scully C. Oral disorders and treatment implications in people over 75 years. Community Dent Oral Epidemiol 1988; 16: 271-273.

22 Abdellatif $\mathrm{H}$ M, Burt B A. An epidemiological investigation into the relative importance of age and oral hygiene status as determinants of periodontitis. J Dent Res 1987; 66: 13-18.

23 Steele J G, Walls A W, Ayatollahi S M, Murray J J. Major clinical findings from a dental survey of elderly people in three different English communities. Br Dent J 1996; 180: 17-23. 